\title{
Light and Electron Microscope Localization of the Microtubule- Associated tau Protein in Rat Brain
}

\author{
Antonio Migheli, ${ }^{1, a}$ Madeline Butler, ${ }^{2}$ Kristy Brown, ${ }^{1}$ and Michael L. Shelanski ${ }^{1}$ \\ 'Department of Pathology, College of Physicians and Surgeons, Columbia University, New York 10032, and ${ }^{2}$ Biology \\ Department, Kean College of New Jersey, Union, New Jersey 07083
}

\begin{abstract}
We have studied the distribution of microtubule-associated tau proteins in rat brain using monoclonal and affinity-purified polyclonal antibodies. Tau staining is prominent in axons in white matter areas of brain, as reported by Binder et al. (1985). In addition, we also find tau protein in neuron cell bodies, especially in the brain stem and basal ganglia and in the cell bodies of interfascicular oligodendroglia. Using electron microscopy, tau antibodies and colloidal gold-labeled second antibodies, gold particles are found associated with microtubules in axons and in the cytoplasm of cell bodies, while the nuclei, mitochondria, and myelin remain unlabeled. In double-staining experiments, tau staining colocalizes with that of tubulin. Our studies indicate that tau proteins are more widely distributed in brain than previously reported and cannot be used as an exclusive marker for axons.
\end{abstract}

Microtubules are a major component of the cytoskeleton in nervous tissue and are especially prominent in neuronal processes, where they are important in outgrowth and axonal transport. Microtubules prepared from brain by cycles of assembly and disassembly (Shelanski ct al., 1973) are composed primarily of tubulin but also contain several microtubule-associated proteins (MAPs) (Murphy and Borisy, 1975; Weingarten et al., 1975), which when added back to pure tubulin, promote assembly. MAPs are believed to regulate microtubule assembly in vivo and may connect microtubules to other cellular structures (Leterrier et al., 1981; Bloom and Vallee, 1983).

MAPs from brain include, among others, the high-molecularweight proteins (HMW), MAP 1 and 2 (approximate molecular weight 300,000 ), and a group of proteins, collectively referred to as tau (approximate molecular weight $56,000-66,000$ ). Tau proteins are extremely heterogeneous, both in molecular weight and isoelectric point (Cleveland et al., 1979; Butler and Shelanski, 1986), but are closely related as shown by similarities in peptide maps and immunological cross-reactivity. The molecular weights of tau exhibit both interspecies variation and developmental regulation (Francon et al., 1982). Both classes of MAPs are phosphoproteins, and it seems likely that the phosphorylation of MAPs modulates their interaction with tubulin

\footnotetext{
Received Dec. 7, 1986; revised Oct. 14, 1987; accepted Oct. 26, 1987.

This work was supported by Grant NS 15076 from the NIH.

Correspondence should be addressed to Michael $\mathrm{L}$. Shelanski at the above address.

a Present address: Clinica Neurologica II dell'Universita di Torino, via Cherasco 15, Turin, Italy.

Copyright $(c) 1988$ Society for Neuroscience $0270-6474 / 88 / 061846-06 \$ 02.00 / 0$
}

in vivo (Greene et al., 1983; Murthy and Flavin, 1983; Drubin et al., 1985).

A significant amount of work has been done on the localization of the HMW MAPs in the nervous system, using immunocytochemical techniques. Whereas MAP 2 is restricted, for the most part, to the soma and dendrites of ncurons, MAP 1 is found in neuronal cell bodies, dendrites, and axons, as well as in oligodendroglia and astrocytes (Bernhart and Matus, 1984; Bloom et al., 1984; Caceres et al., 1984). The distribution of tau in the nervous system is less well understood. The results of earlier work using uncharacterized polyclonal antibodies are ambiguous, and only Binder et al. (1985) have studied tau distribution using a well characterized monoclonal antibody to tau. These investigators claimed that tau proteins are uniquely localized to axons in rat brain.

Using monoclonal and affinity-purified polyclonal anti-tau antibodies, we have re-evaluated the distribution of tau in the nervous system, at both the light and electron microscope level, and find its distribution more widespread than previously reported.

\section{Materials and Methods}

Antibody production. The monoclonal and affinity-purified polyclonal antibodies used in this work have been characterized and described in previous work. They all recognize all the forms of tau in cow, human, and rat brain. The guinea pig affinity-purified polyclonal (Butler and Shelanski, 1986) was produced and purified in our laboratory and recognizes only tau on immunoblots of whole brain. The monoclonal $\mathrm{H} 2$ is an IgM that recognizes tau on whole-brain blots, as well as a highermolecular-wcight putative tau protcin (approximate molccular weight $110,000)$ (Peng et al., 1986). Another monoclonal antibody to tau proteins, Tau-1, was generously provided by Dr. Lester Binder (Binder et al., 1985). The antiglial filament protein polyclonal rabbit antibody and the antineurofilament monoclonal antibody were provided by Dr. Ronald Liem, and the polyclonal antitubulin was produced in this laboratory.

Immunocytochemical methods. Adult Sprague-Dawley rats were anesthetized with Nembutal $(50 \mathrm{mg} / \mathrm{kg}$ ) and were perfused intracardially with $10 \mathrm{ml}$ of PBS (10 mM sodium phosphate, $0.15 \mathrm{M} \mathrm{NaCl}, \mathrm{pH} 7.4$ ) and then $100 \mathrm{ml}$ of one of the following fixatives at room temperature: (1) 4\% paraformaldehyde in PBS; (2) 4\% paraformaldehyde in PBS, with varying amounts of glutaraldehyde up to $0.5 \%$; (3) same as 2 , but containing $0.2 \%$ picric acid. After perfusion, the brains were removed and immersed in the fixative for three hours. Tissue was cut into blocks and rinsed in PBS overnight at $4^{\circ} \mathrm{C}$, or, in the case of frozen sections, the blocks were equilibrated with $30 \%$ sucrose in PBS.

Light microscopy. Tissue sections were cut either with a cryostat (10 $\mu \mathrm{m}$ thick) or on a vibratome ( $70-100 \mu \mathrm{m}$ thick). All antibody dilutions, incubations, and washes were done in PBS at room temperature unless otherwise stated. Vibratome sections were processed using the $\mathrm{ABC}$ immunoperoxidase method (Vector Laboratories); incubations were as follows: $3 \%$ hydrogen peroxide for $15 \mathrm{~min}, 10 \%$ normal goat serum for $1 \mathrm{hr}$, first antibody overnight at $4^{\circ} \mathrm{C}$, biotinylated second antibody for 

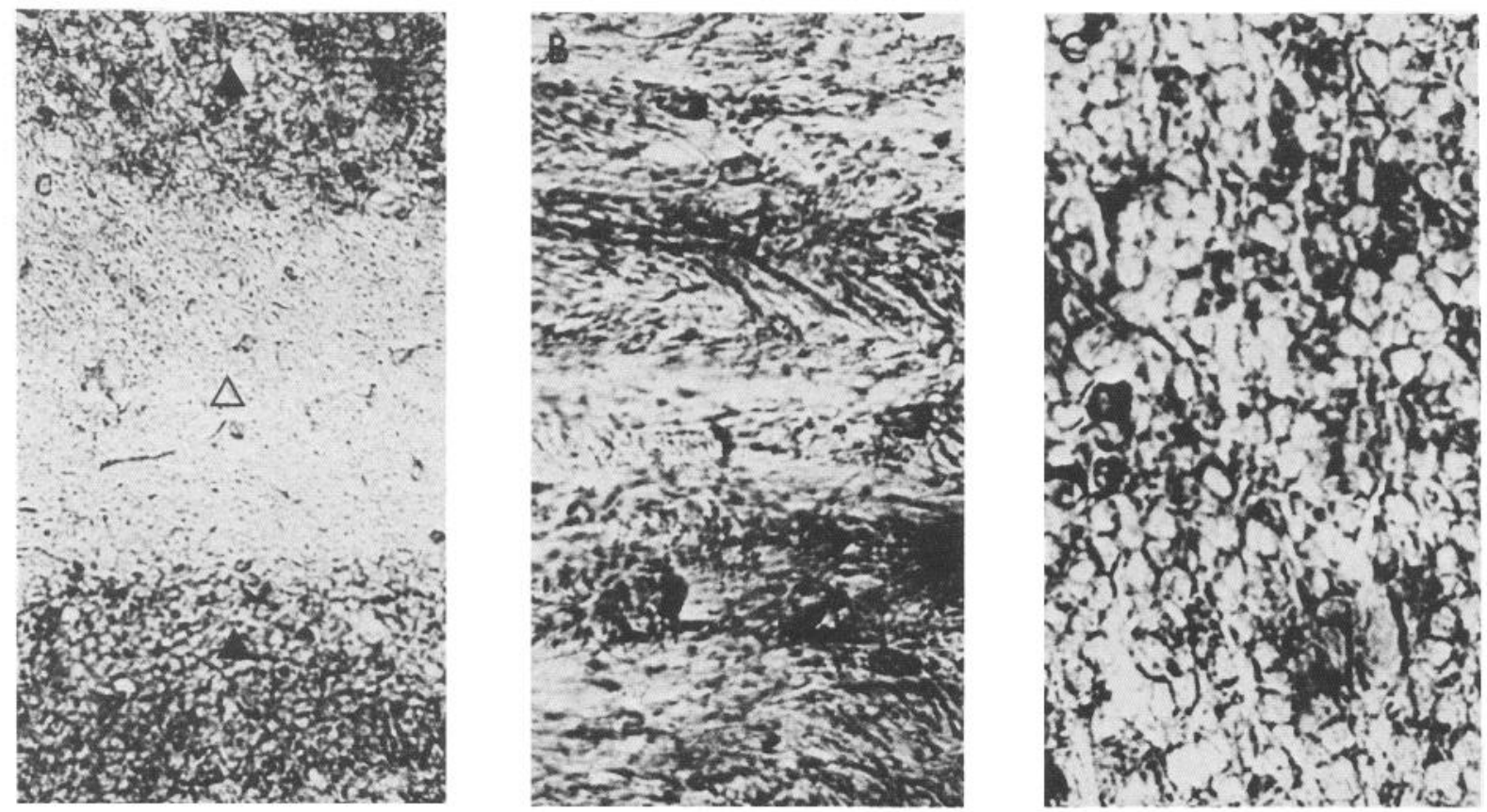

Figure 1. Immunoperoxidase localization of microtubule-associated tau protein on vibratome sections of rat cerebellum. $A$, Staining of cerebellar white matter (open triangle) and granule cell layer (closed triangles) with Tau-1 antibody (axons are cut transversely in this section). $\times 150$. B, Staining of white matter with affinity-purified guinea pig antibody on a vibratome section of rat cerebellum. Axons are heavily stained in all white matter areas of brain. $\times 300$. C, Staining of granule cell perinuclear cytoplasm with Tau- 1 antibody. $\times 300$.

$1 \mathrm{hr}$ at room temperature, and avidin-biotin complex for $2 \mathrm{hr}$. Sections were washed extensively between incubations. Sections were developed in $0.005 \%$ hydrogen peroxide and $0.05 \%$ diaminobenzidine in $50 \mathrm{~mm}$ Tris, $\mathrm{pH} 7.0$, and were washed and mounted on slides. The sections were air-dried, cleared, and mounted in Permount. Frozen sections were incubated with primary antibody overnight, and the sections were then incubated for $1 \mathrm{hr}$ with fluorescent second antibodies (Cappel Laboratories) and mounted on slides in $16 \%$ polyvinyl alcohol in $33 \%$ glycerol. In the case of negative controls, sections were treated similarly, except that the primary antibody was omitted.

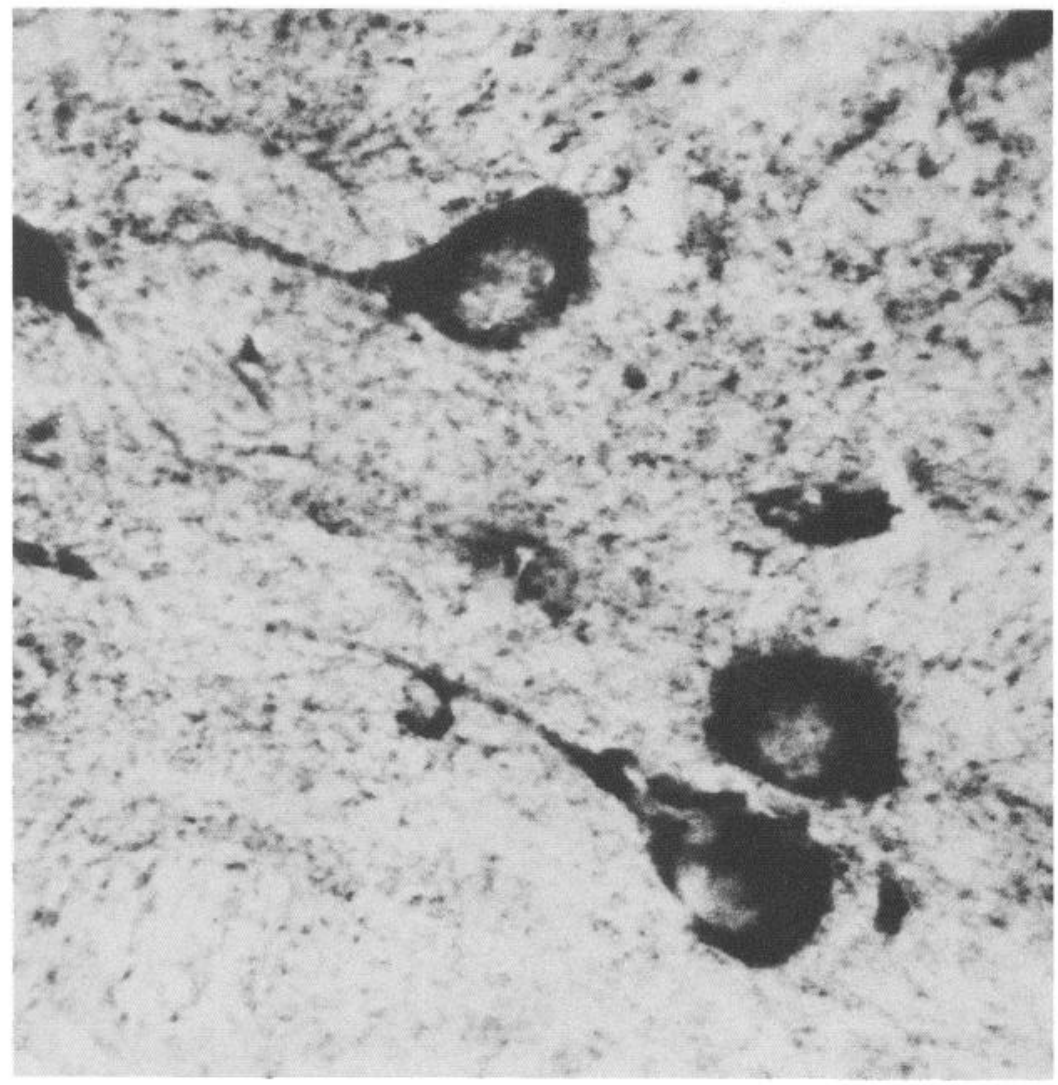

Figure 2. Immunoperoxidase localization of tau proteins on a section of rat basal ganglia, using Tau- 1 antibody. Note the positively stained neuronal cell body and initial segments of the dendrites. $\times 500$. 

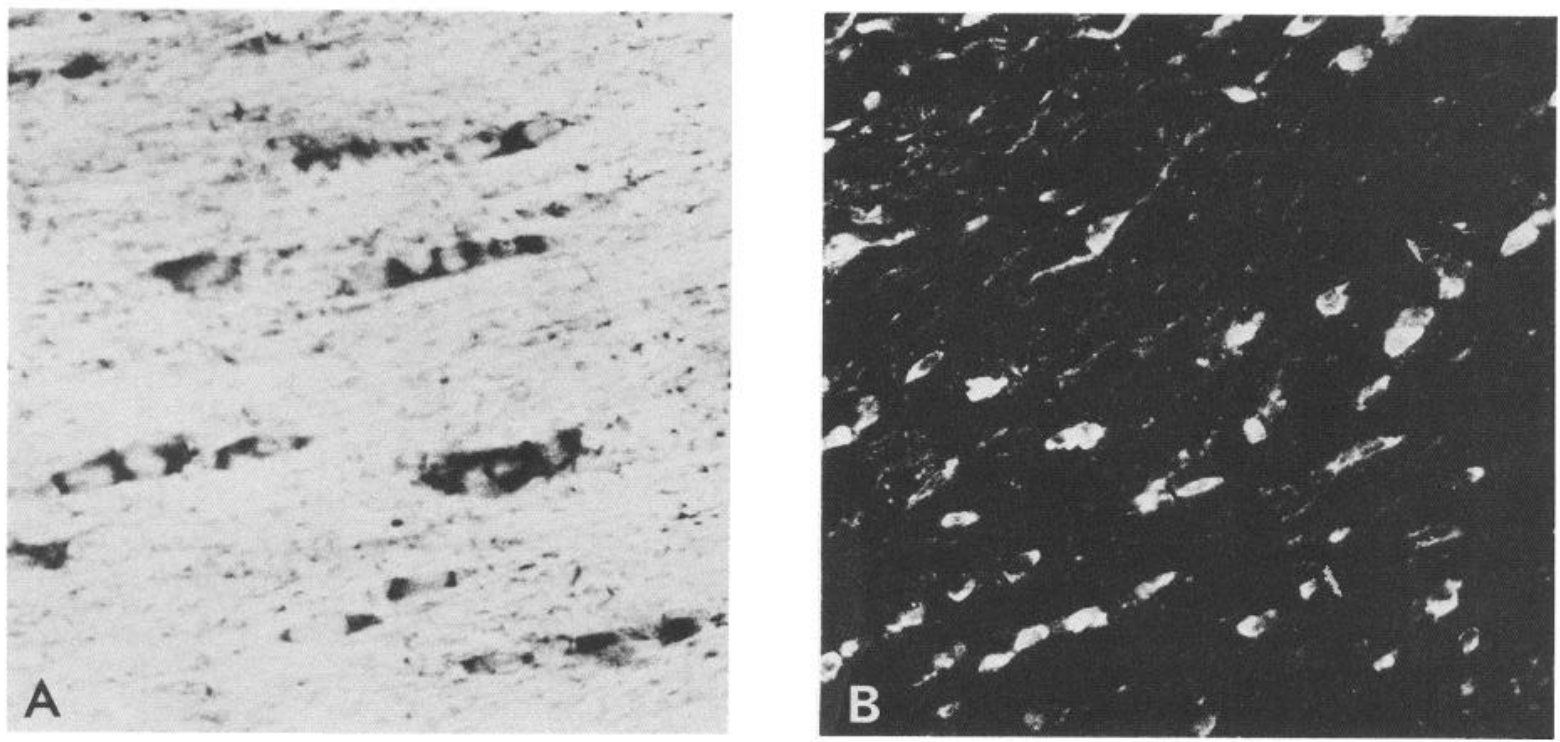

Figure 3. A, Immunoperoxidase localization of tau proteins using Tau-1 antibody on a vibratome section of corpus callosum. $\times 320$. B, Immunofluorescent localization of tau proteins using monoclonal $\mathrm{H} 2$ antibody on a frozen section of internal capsule. In both areas of rat brain, tau antibodies stain both axons and oligodendroglia-like cell bodies. $\times 160$.

Electron microscopy. Lowicryl K4M was used for preembedding of fixed tissue, according to Roth et al. (1981) and Valentino et al. (1985) with some modifications. Tissue was dehydrated in ethanol at either $4^{\circ} \mathrm{C}$ or room temperature. Infiltration with Lowicryl was prolonged for up to $48 \mathrm{hr}$ in order to improve morphology of brain tissue. The Lowicryl blocks were polymerized in a chamber using ultraviolet light. Silver sections were cut and then picked up on Formvar-coated nickel grids. Sections were then stained as follows: The grids were floated on $5 \%$

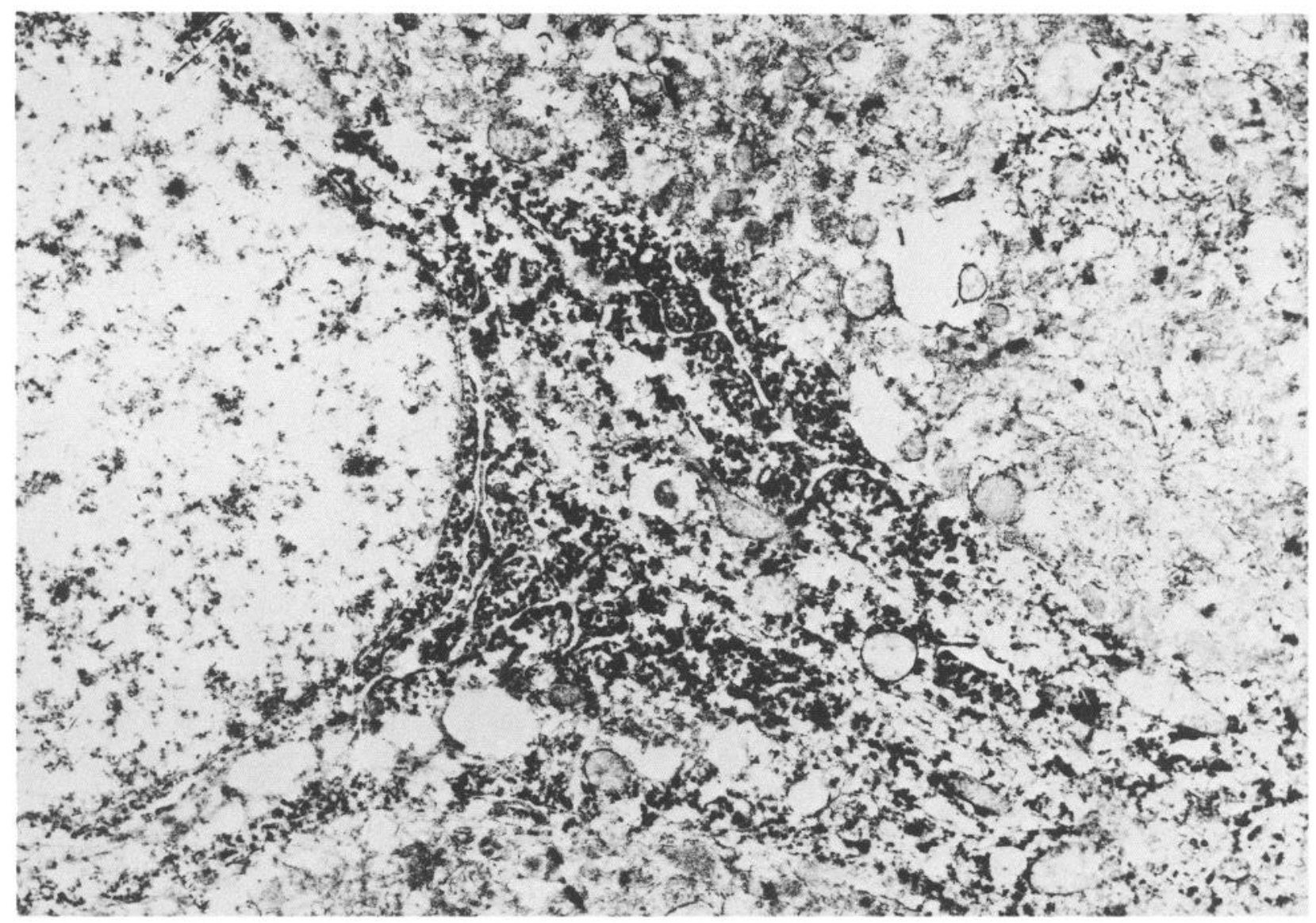

Figure 4. Electron microscope immunoperoxidase localization of tau proteins using affinity-purified guinea pig antibodies on a vibratome section of basal ganglia. Staining is intense in cell body of neuron and process (upper right corner), while much of the neuropil and the cell nucleus are negative. $\times 112,500$. 
normal goat serum in PBS for $1 \mathrm{~min}$, on the first antibody for $7 \mathrm{~min}$, rinsed $3 \times 1 \mathrm{~min}$, and floated on gold-labeled second antibody for 2 min. The sections were then vigorously washed in PBS and fixed in $2.5 \%$ glutaraldehyde. The sections were finally stained in $2 \% \mathrm{OsO}_{4}$ for $10 \mathrm{~min}$ and $2 \%$ uranyl acetate for $5 \mathrm{~min}$.

Ultrathin frozen sections were obtained from blocks of fixed tissue and stained following the procedure of Tokuyasu (1984). Single and double immunogold staining were performed using 5 and $10 \mathrm{~nm}$ gold labeled second antibodies.

\section{Results}

Sections obtained from cerebrum, cerebellum, brain stem, and spinal cord of the adult rat brain were analyzed for positive reactions after immunocytochemical staining with anti-tau antibodies. Axons appeared to be positively stained in all the areas studied, in accord with previous observations of Binder et al. (1985). Axonal staining was especially strong in the internal capsule, the corpus callosum, and the cerebellar white matter (Fig. 1, $A, B$ ). However, in contrast to the results of Binder, strong staining of neuronal cell bodies in certain areas of the brain was also observed. For example, granule cells in the cerebellum were positive for tau (Fig. 1, $A, C$ ), although Purkinje cells were mostly negative. Neuronal cell bodies in the basal ganglia and the brain stem were most heavily stained, and the initial segments of their dendrites were also stained (Fig. 2). Neurons in the cortex and hippocampus were more weakly and less consistently stained. Similar results were obtained with all the tau antibodies used.

Also in contrast to the results of Binder et al. (1985), we obtained staining of intrafascicular oligodendroglia. Staining was especially strong in the white matter of the corpus callosum and internal capsule (Fig. 3, $A, B$ ). Cell clusters and rows of 3-5 cells in between the stained axon bundles were clearly positive for tau. As positive controls, sections were stained with monoclonal antineurofilament antibodies, and polyclonal antitubulin and antiglial filament antibodies. Tubulin-stained cell bodies and processes of neurons, while neurofilament antibodies primarily stained large axons. Based on similar comparisons with sections stained with glial filament antibodies, sections stained with tau antibodies did not appear to contain reactive astrocytes.

The observations of tau staining were confirmed with ultrastructural analysis. In vibratome sections stained with the immunoperoxidase technique, reaction product was observed in neuronal cell bodies and in processes (Fig. 4). In particular, microtubules were stained in the processes, and the cell bodies contained a diffuse granular product in the cytoplasm, while the mitochondria and the nuclei were negative. Similar results were obtained using colloidal gold-labeled second antibodies, ruling out artifacts due to diffusion of reaction product. Though the lack of signal amplification in this technique decreases sensitivity, gold particles could be localized to the cytoplasm, while other structures such as nuclei, blood vessels, mitochondria, and myelin were negative. Axons were found to be richest in gold particles, and the gold particles were often seen linked to microtubules (Fig. 5A); however, apparently free gold particles were also seen, especially in the cell bodies. Control sections contained scattered gold particles at much lower densities (Fig. $5 B)$.

In frozen sections, double stained with anti-tubulin and antitau antibodies and colloidal gold-labeled second antibodies of different sizes, the gold particles colocalized in axons (Fig. 6) and neuronal perikarya. Tubulin staining was stronger than that of tau, reflecting the higher tubulin concentration present in
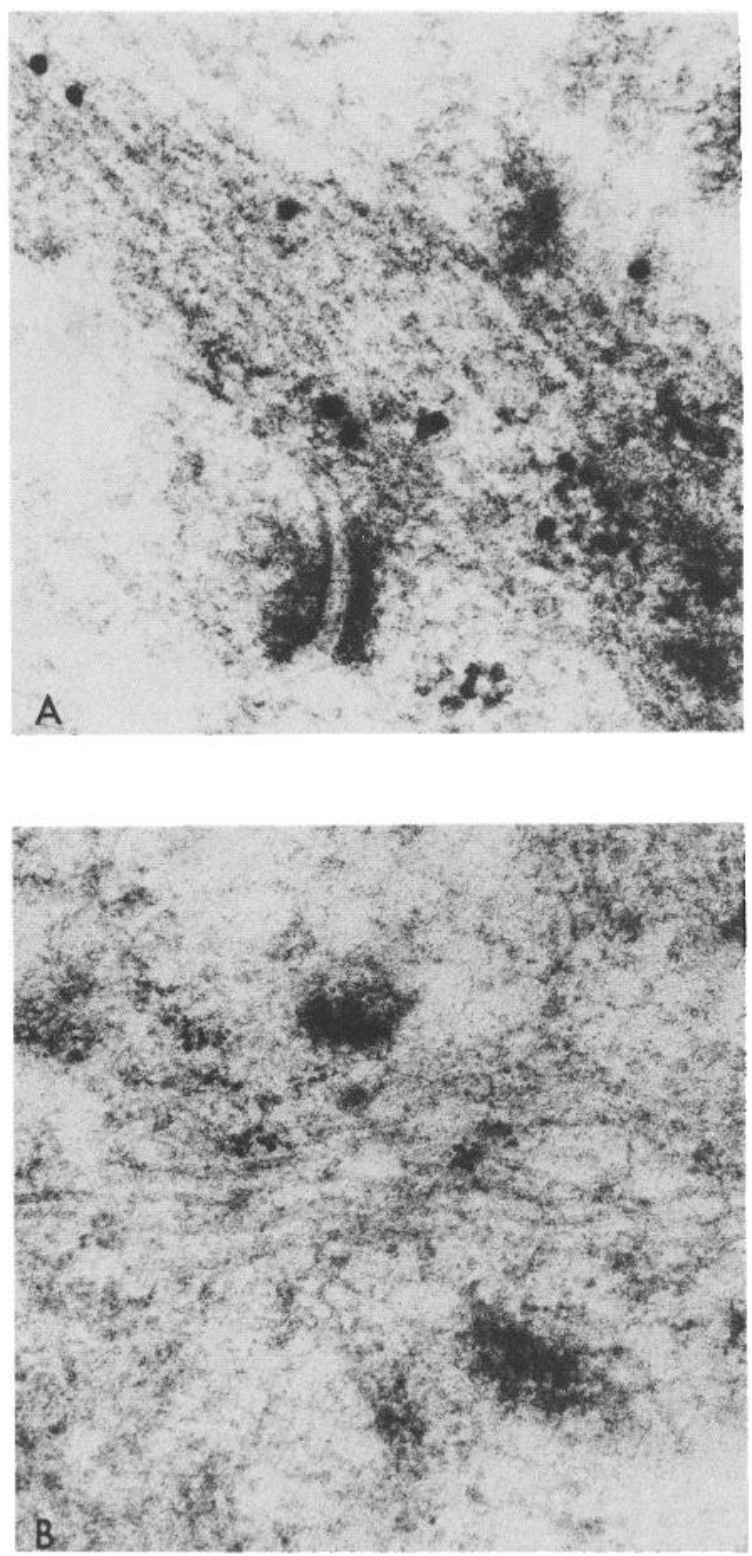

Figure 5. A, Immunogold localization of tau proteins using $\mathrm{H} 2$ antibody and $20 \mathrm{~nm}$ gold-labeled second antibody on a Lowicryl embedded section of rat cerebellum. Gold particles were concentrated on intact microtubules. $\times 100,000$. $B$, Negative control of similar region of cerebellum. $\times 45,000$.

nervous tissue. As a control for tau staining in tissue, microtubules assembled in vitro were stained with tau antibodies. Staining on assembled microtubules appeared to be specific, and, in some places, a regular distribution of gold particles along a microtubule could be observed (Fig. $7 A$ ).

\section{Discussion}

Although the localization of the HMW MAPs has been extensively studied, very little data exists on the localization of tau in nervous tissue. Studies using a polyclonal antibody, which was neither characterized by immunoblotting nor affinity-purified, showed widespread distribution of tau in different cell types, including fibroblasts (Connolly and Kalnins, 1980). Recently, Binder et al. (1985) used a tau-specific monoclonal antibody to perform biochemical and immunocytochemical studies and 


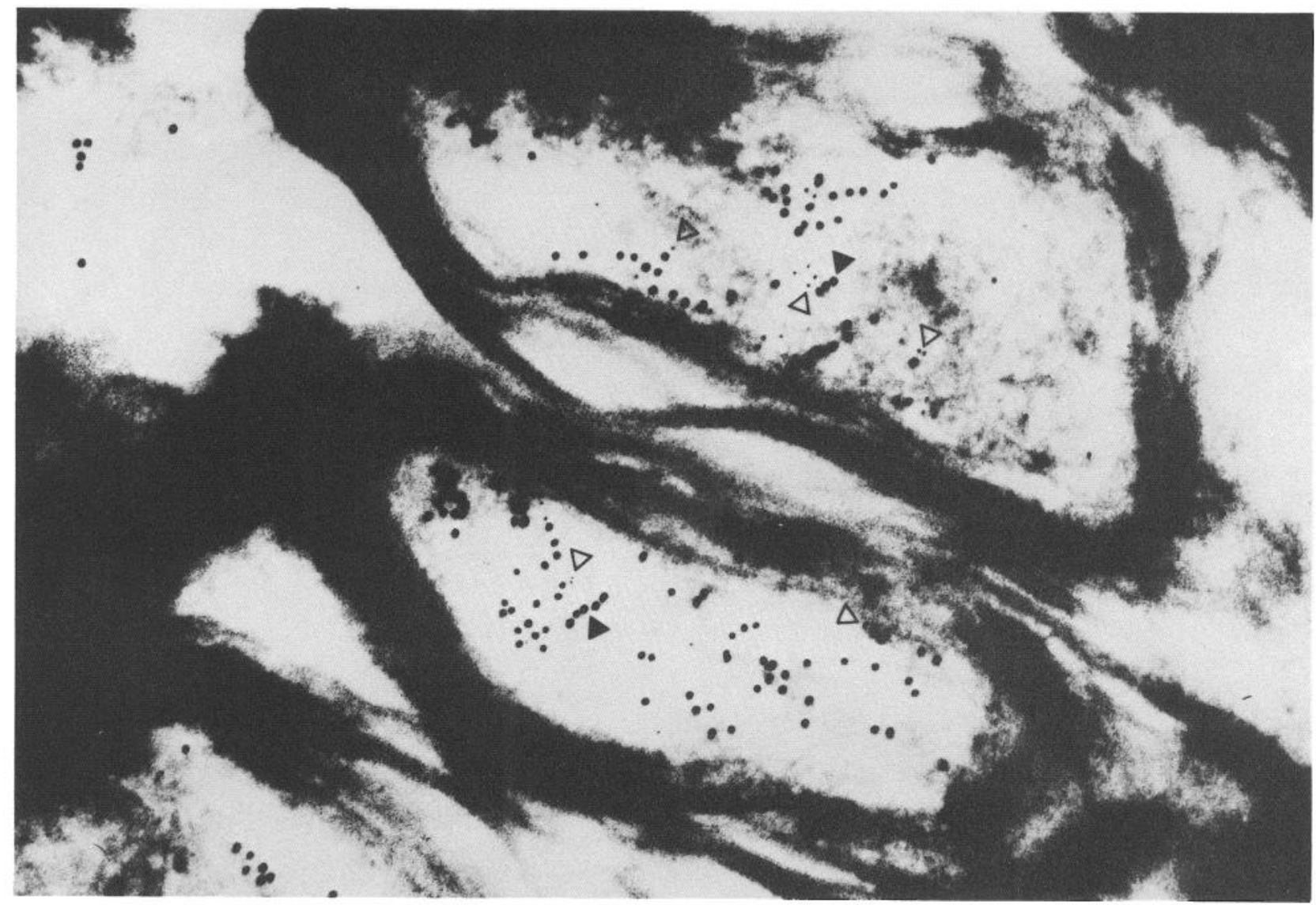

Figure 6. Immunogold localization of tubulin using affinity-purified rabbit polyclonal antibody and 10 nM gold-labeled second antibodies (closed arrows) and tau using Tau- 1 antibody and $5 \mathrm{~nm}$ gold-labeled second antibody (open arrows), on ultrathin frozen section of rat spinal cord. $\times 106,000$. Note that the 2 sizes of gold particles colocalize in the axoplasm, but the tubulin staining is stronger.

concluded that tau is concentrated in the white matter of brain. Tau staining was limited to axons in the areas studied, namely, the medulla, substantia nigra, and cerebellum. Using tau-specific monoclonal antibodies and an affinity-purified polyclonal antibody, we have reevaluated and extended the light microscopic observations of Binder et al. (1985). With all the antibodies used, axonal staining in the rat brain and spinal cord was prominent. However, in contrast to the results of Binder, we also obtained significant staining of neuronal cell bodies in certain parts of the brain, most noticeably the basal ganglia and brain stem, as well as staining of oligodendroglial cell bodies.

In order to confirm these observations and to determine if tau proteins are associated with microtubules in vivo, we extended our studies of tau localization using electron microscopy. The electron microscope studies using tau antibodies and colloidal gold-labeled second antibodies support our light microscope observations in that gold particles were found in both cell bodies and axons. In addition, gold particles could be localized to intact microtubules, and tau staining colocalized with that of tubulin.

Although our observations confirm that tau staining of axons is especially prominent in rat brain (Binder et al., 1985), our results differ in several significant ways. Both the staining of neuronal cell bodies and the observation that tau is present in oligodendroglia were unexpected based on the results of Binder et al. However, from a biological standpoint these new observations are not surprising, since tau must be synthesized in the cell body before being transported into the axon, and oligodendroglia are known to contain high levels of microtubules (McCarthy and de Vellis, 1980), as well as MAP 1 (Bloom et al., 1984).

In order to rule out the possibility that our results were due to nonspecific staining, we used several different tau antibodies, and we compared tau staining to that of other antibodies whose distribution in brain have been well characterized. Our studies indicate that tau reactivity is more readily lost on fixation than either tubulin or glial filament reactivity. The sensitivity of tau coupled with its low levels in tissue suggests that even slight variations in fixation procedures may make a crucial difference in the detection of tau. It is possible that there are many areas, such as cell bodies, where tau levels are low and less readily detected, and that one technique might permit its detection or antibody accessibility while another will not.

Further detailed immunocytochemical studies on the localization of tau in nervous tissue need to be done in order to determine if differences in the distribution of tau between specific neuronal and axonal populations exist. The fact that some neurons in brain stain with tau antibodies, while others do not may indicate that either tau accessibility or tau levels vary in different populations of neurons. Tau proteins are very heterogeneous (Butler and Shelanski, 1986), but available tau antibodies appear to recognize all forms of tau so that studies on differences in the distribution of tau isoforms are not yet possible. It is apparent from our studies, however, that tau proteins 

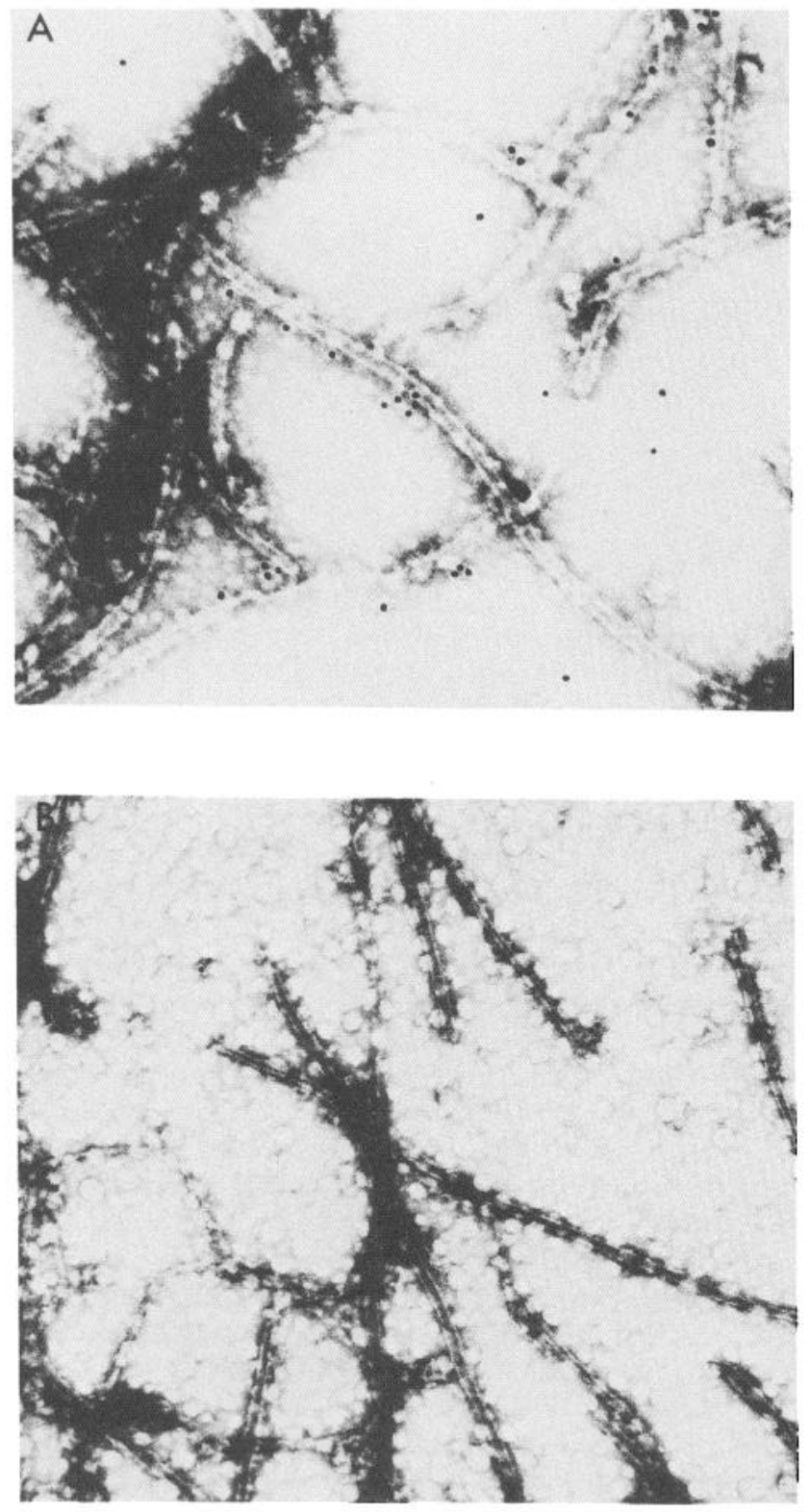

Figure 7. A, Immunogold localization of tau proteins on twice-cycled microtubules dropped on Formvar-coated grids, using antibody $\mathrm{H} 2$ and $10 \mathrm{~nm}$ gold-labeled second antibodies. $\times 70,500 . B$, Negative control of same preparation of microtubules. $\times 62,500$.

are not limited to axons and are more widely distributed in the nervous system.

\section{References}

Bernhardt, R., and A. Matus (1984) Light and electron microscopic studies of the distribution of microtubule-associated protein 2 in rat brain: A difference between dendritic and axonal cytoskeletons. J. Comp. Neurol. 226: 203-221.

Binder, L. I., A. Frankfurter, and L. I. Rebhun (1985) The distribution of tau in the mammalian nervous system. J. Cell Biol. 101: 13711378.

Bloom, G. S., and R. B. Vallee (1983) Association of microtubuleassociated protein 2 (MAP 2) with microtubules and intermediate filaments in cultured brain cells. J. Cell Biol. 96: 1523-1531.

Bloom, G. S., T. A. Schoenfeld, and R. B. Vallee (1984) Widesperad distribution of the major polypeptide component of MAP1 (micro- tubule-associated protein 1) in the nervous system. J. Cell Biol. 98: 320-330.

Butler, M., and M. L. Shelanski (1986) Microheterogeneity of microtubule-associated tau proteins is due to differences in phosphorylation. J. Neurochem. 47: 1517-1522.

Caceres, A., L. I. Binder, M. R. Payne, P. Bender, L. Rebhun, and O. Steward (1984) Differential subcellular localization of tubulin and the microtubule-associated protein MAP2 in brain tissue as revealed by immunocytochemistry with monoclonal hybridoma antibodies. J. Neurosci. 4: 394-410.

Cleveland, D. W., B. M. Spiegelman, and M. W. Kirschner (1979) Conservation of microtubule-associated proteins. J. Biol. Chem 254: 12670-12678.

Connolly, J. A., and V. I. Kalnins (1980) The distribution of tau and HMW microtubule-associated proteins in different cell types. Exp. Cell Res. 127: 341-350.

Drubin, D. G., S. C. Feinstein, E. M. Shooter, and M. W. Kirschner (1985) Nerve growth factor-induced neurite outgrowth in PC 12 cells involves the coordinate induction of mictotubule assembly and assembly-promoting factors. J. Cell Biol. 101: 1799-1807.

Francon, J., A. M. Lennon, A. Fellous, A. Mareck, M. Pierre, and J. Nunez (1982) Heterogeneity of microtubule-associated proteins and brain development. Eur. J. Biochem. 129: 465-471.

Greene, L. A., R. K. Liem, and M. L. Shelanski (1983) Regulation of a high molecular weight microtubule-associated protein in PC 12 cells by nerve growth factor. J. Cell Biol. 96: 76-83.

Leterrier, J. F., R. K. H. Liem, and M. L. Shelanski (1981) Preferential phosphorylation of the 150,000 molecular weight component of neurofilaments by a cyclic AMP-dependent microtubule-associated protein kinase. J. Cell Biol. 90: 755-760.

McCarthy, K. D., and J. de Vellis (1980) Preparation of separate astroglial and oligodendroglia cell cultures from rat cerebral cortex. J. Cell Biol. 85: 890-902.

Murphy, D. B., and G. G. Borisy (1975) Association of high-molecular-weight proteins with microtubules and their role in microtubule assembly. Proc. Natl. Acad. Sci. USA 72: 2696-2700.

Murthy, A. S. N., and M. Flavin (1983) Microtubule-associated protein MAP-2 prepared in defined states of phosphorylation with protein kinase and phosphatase. Eur. J. Biochem. 137: 37-46.

Peng, I., L. I. Binder, and M. M. Black (1986) Biochemical and immunological analyses of cytoskeletal domains of neurons. J. Cell Biol. 102: 252-262.

Roth, J., M. Bendayan, E. Carlemalm, W. Villiger, and R. M. Garavito (1981) Enhancement of ultrastructural preservation of immunocytochemical staining in low temperature embedded pancreatic tissue. J. Histochem. Cytochem. 29: 663-671.

Shelanski, M. L., F. Gaskin, and C. R. Cantor (1973) Microtubule assembly in the absence of added nucleotides. Proc. Nal. Acad. Sci. USA 70: 765-768.

Tokuyasu, K. T. (1984) Immuno-cryoultramicrometry. In Immunolabelling for Electron Microscopy, J. M. Polak and I. M. Varndell, eds., pp. 71-82, Elsevier, Amsterdam.

Valentino, K. L., D. A. Crumrine, and L. F. Reichart (1985) Lowicryl K4M embedding of brain tissue of immunogold electron microscopy. J. Histochem. Cytochem. 33: 969-973.

Weingarten, M. D., A. H. Lockwood, S. Hwo, and M. W. Kirschner (1975) A protein factor essential for microtubule assembly. Proc. Natl. Acad. Sci. USA 72: 1858-1862. 